\title{
Scientific instrumentarium for diagnostics of staffing at the Ukrainian machine-building enterprises: marketing approach
}

\author{
Kateryna Pryakhina ${ }^{1 *}$, Andryi Pochtovyuk ${ }^{1}$ \\ ${ }^{1}$ Kremenchuk Mykhailo Ostrohradskyi National University, Pershotravneva Street 20, 39600 \\ Kremenchuk, Ukraine
}

\begin{abstract}
The article deals with scientific instrumentarium for diagnostics of staffing of Ukraininan machine-building enterprisesthanks to a set of methods and techniques of scientific knowledge (analysis to determine the conformity of production and economic objectives to staffing, Synthesis to investigate the quantitative dynamics of staff by typing posts, assessments to identify the inadequate level of professional and qualification correspondenceof the employee with the requirements of the employer), which allows to determine the causes of the problems of staffing.This will allow in the future to form a system of scientific and practical measures to bring the professional qualifications of the workers into line with the needs of employers in accordance with the portfolio of the orders of the enterprise. Key words: staffing, marketing approach, machine-building enterprises, professional and qualification correspondence, conformity class
\end{abstract}

\section{Introduction}

The state of the development of machine-building enterprises is directly illustrated by the economic vector of the national economy and indirectly by the social basis in Ukrainian society.In order to meet the high mission of the society entrusted to machine building, enterprises of the industry should be guided by the external market environment, that is, in time to adapt to consumer preferences. Taking into account the constant nature of the changes in the market environment, the activities of machine-building enterprises should constantly adjust their own resources to the technological requirements of order execution. This refers to the component of activity as personnel management. Staffing is one of the most important aspects of human resources management, which needs new approaches to improve performance in changing business conditions. Marketing is one of the effective aspects of the formation of effective staffing in the modern conditions. The marketing approach to staffing means, that profession and qualification at the same timeare characteristics of the personnel needs of employers and proposals from the employees. Staffing of the enterprise is a complex of measures, which allows maximum achievement of professional-qualification balance of the needs of employers and the qualities of employees.

${ }^{*}$ Corresponding author: katerinapryakhina@gmail.com 


\section{Data and Methods}

To solve the tasks, a wide range of theoretical and empirical methods of scientific knowledge was used: scientific abstraction - in determining the categorical apparatus of the staff of machine-building enterprises on the principles of marketing; diagnostic - in the building tools for personnel support; deductions and analogies - when combining the general (branch) and individual (enterprise subdivision) levels of research; combinatorics and grouping - in determining the qualification characteristics; synthesis - in the classification of types of positions on the basis of the vector and intensity; convergence - in determining the level of professional and qualification correspondence of the qualities of employees to the requirements of the employer, respectively, occupied position; graphic image - for a visual reflection of the results of the study.

The information and empirical base is the data of the State Statistics Service of Ukraine, reports of the leading machine-building enterprises of Ukraine, monographic research materials of domestic and foreign scientists, Internet resources. Sources of initial information are the materials of their own research. The legal basis for scientific research is the Laws of Ukraine, the Decree of the Cabinet of Ministers of Ukraine, the Economic Code of Ukraine.

\section{Results}

The choice of diagnostics is due to the fact that its object may be: the enterprise as a whole as a production-economic system, its elements; operation of separate units, production functions, activities. Diagnostic analysis determines the objective state of the selected parameters in the enterprise in accordance with the goals and objectives set, the study of deviations from the normal state of the object of diagnosis, the causes of these deviations, the duration of their course, their interpretation for the formation of conclusions and recommendations. The method of diagnosis - a system of theoretical and cognitive categories, scientific instruments and regulatory principles of research activities of subjects of management. The basis of the diagnostics of staffing is the triad of methods: analysis, synthesis and evaluation. In this case, the diagnosis involves an assessment of staffing. Consequently, the scientific instrumentarium for the diagnostics of human resources provision of enterprises consists of independent and simultaneously interconnected three stages, envisaging 24 procedures (Fig.1).

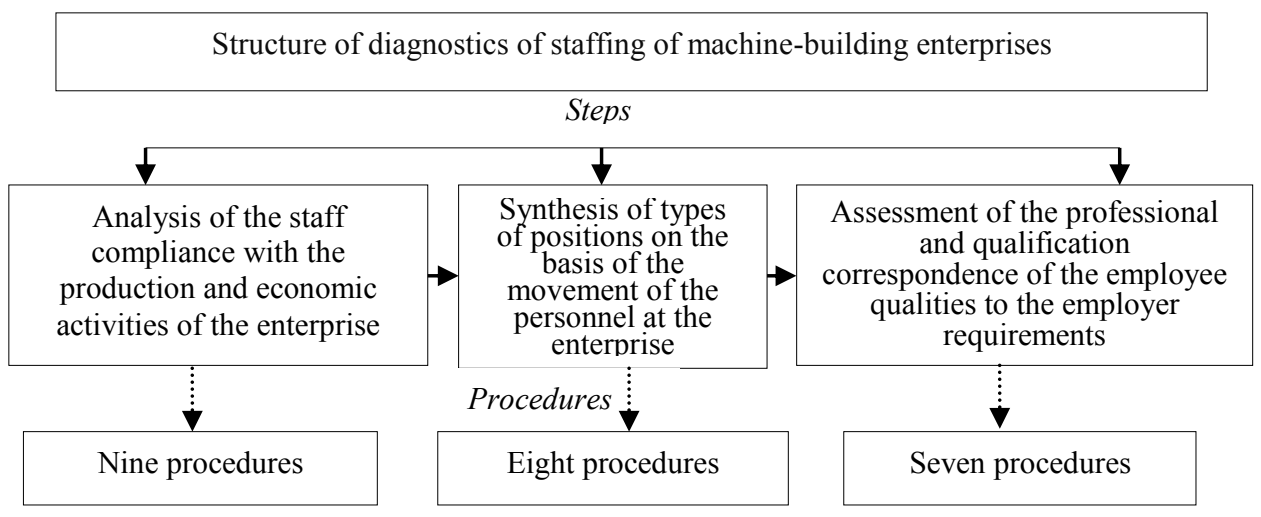

Fig. 1. Structure of diagnostics of staffing of machine-building enterprises

Source: Authors. 
The first stage of the diagnostic assessment involves an analysis of the staff compliance with the production and economic activities of the enterprise and consists of nine procedures. The first procedure determines the investigated enterprises. Personnel support is unexplored in terms of sector specificity, because the work of personnel requires specific properties for the industry. The specialization in in machine building is determined by the profile of machine-building enterprises.

The second procedure is to determine the time limits of the study. If $i$ is a period of research (years), it is determined $\{2011-2018\}$.

The third procedure is to determine the list of indicators. The personnel policy of the enterprise is derived from its production activities and is aimed at increasing the profit of the enterprise. The study has selected absolute indicators that characterize the financial and economic activities of the companies - "net revenue from sales of products (goods and services)" and marked with a symbol $W_{i}$. Indicators that determine personnel policy are "payroll fund", "the average number of employees" and "share of the wage fund in the volume of sales". Payroll fund be symbolized $F_{i}$, the average number of employees $-S_{i}$, and share of the wage fund in the volume of sales $-d_{i}$.

The fourth procedure is the justification for evaluating the change in the results of economic activity of enterprises by means of statistical indicators: average level of interval series of dynamics with even intervals $\bar{Y}$, indicator of the rate of increase $T_{n p}^{l}$ and the average indicator of the rate of increase $\bar{T}_{\text {пр. }}^{\text {л }}$. For analysis, such synthetic indicators are used: $T_{p}^{l} W-$ "rate of increase of net revenue from sales over the period", $T_{n p}^{l} F_{i}$, - "rate of increase the payroll fund", $T_{\text {пр. }}^{\text {л }} S_{i}$ - "rate of increase of the average number of employees", $T_{n p}^{l} d_{i}$ - "rate of increase of the share of the wage fund in the volume of sales"; $\bar{T}_{\text {пр. }}^{\text {л }} W_{i}$ - "average growth rate of net revenue from sales over the period", $\bar{T}_{\text {пр. }}^{\text {л }} S_{i}$ - "average growth rate of the average number of employees", $\bar{T}_{\text {пр. }}^{\text {л }} F_{i}$ - "average growth rate of the payroll fund"; $\bar{Y}\left(W_{i}\right)$ - "the average level of the interval series of dynamics of net revenue from sales of products", $\bar{Y}\left(F_{i}\right)$ - "the average level of the interval series of dynamics the payroll fund", $\bar{Y}\left(S_{i}\right)$ - "the average level of the interval series of dynamics the average number of employees", $\bar{Y}\left(d_{i}\right)$ - "the average level of the interval series of dynamics the wage fund in the volume of sales".

The fifth procedure is the definition of the compliance of human resources with the production and economic activity of the enterprise. With regard to economic expediency, the increase in sales proceeds leads to an increase in the payroll fund and the average number of employees and vice versa. As an example of three or more sub-sector enterprises, it is necessary to analyze the availability of this dependence. The analysis will prove the same tendency of the values: an increase in sales revenue will lead to an increase in the number of employees of the enterprise, which in turn will reflect such a trend towards the wage fund and the wage fund in the volume of sales, or it will detect a lack of correlation of indicators.

The sixth procedure is the selection of the structural unit of the enterprise for research. Taking into account the identity of the indicators of the sub-sector of machine-building complex and the marketing approach to personnel provision, which involves the personalized relations between employees and employer.

The seventh procedure provides for the description of the nomenclature of the products of the structural unit in the context of the needs of the personnel of the corresponding profession and qualification. Nomenclature of products reflects the full spectrum of technological operations, which respectively require personnel support. At the same time, taking into account sector specifics, each machine-building enterprise has its own portfolio of orders in accordance with its capacity and technological process. In today's management environment, the portfolio of orders of enterprise is constantly changing, the company can have both one order and $n$. Therefore, an enterprise portfolio can be defined: 


$$
P=\sum_{1}^{n} x_{n}
$$

where, $\mathrm{P}$ - portfolio of enterprise orders, $x_{n}$ - order of the enterprise, $n$ - serial number of the contract in the period. The portfolio of orders consists of predefined objects for the production of which the availability of resources and factors of production is required. In view of the marketing concept for efficient and balanced activity of the enterprise, this resource potential should be formed for each individual order.

The eighth procedure determines the calculation of the needs of the personnel of the relevant profession and qualification, as an example of two or more orders of the company that were in the portfolio of orders. This calculation was carried out with the help of a technological card naming products, which characterizes the interaction of technological processes. Each operation involves availability professionally qualified personnel and calculation of labor intensity.

Thus, the ninth, the last procedure of the first stage of diagnosis characterizes the generalization of the possibility of forming a staffing of the enterprise in accordance with contracts that make up a portfolio of orders.

The second stage of the diagnostic assessment is the synthesis of types of positions on the basis of the movement of the personnel at the enterprise, which consists of eight procedures. The tenth procedure determines the choice of a structural unit for further research, because in this structural unit main technological operations are executed (first stage). At the same time, the choice of the shop is justified by the use of methods of analogy and deduction.

There is a refinement from the general to the separate, that is, from the research of enterprises in the sub branch or industry to the structural unit, which ensures the implementation of major technological processes. The staffing of the enterprise is formed taking into account the specifics of its activity and the personified nature of labor relations. The method of analogy in the formation of staffing of the structural unit allows to generalize the staffing of enterprises in the sub-sector as a whole.

The eleventh procedure involves determining the range of indicators that demonstrate the movement of the staff in the structural unit [1]. Indicators are indicated by: $n_{i}^{j}-$ "the number of staff to the end $i$ period", $\hat{n}_{i}^{j}$ - "the number of accepted employees during $i$ period", $\check{n}_{i}^{j}-$ "the number of dismissed workers within $i$ period", $d_{n_{i}^{j}}$ - "part $j$ categories of employees in accordance with the categories of the Ukrainian Classifier of professions in the total number of employees of the structural unit" [2], where $i-$ "the period of the studied period (calendar year)", the value is reduced to the last two digits of the year, so for example $i=\{11-18\}$. Scope of definition $j$ categories equals $j=\{4.1,4.2,4.3,4.4,4.7,4.8,4.9\}, 4.1-4.9-$ sections of the Ukrainian Classifier of professions.

The twelfth procedure determines the synthetic indicators in accordance with the absolute regarding the movement of the structural unit : $\mathrm{T}_{\text {пр }}^{\pi} N_{\mathrm{i}}$ - "chain rate of increase of staff', $\mathrm{T}_{\text {пр }}^{\pi} \widehat{N}_{i}$ -"chain rate of increase the number of accepted employees", $\mathrm{T}_{\text {пр }}^{\pi} \widehat{N}_{i}$ - "chain rate of increase the number of dismissed workers", $\bar{T}_{n p}^{\pi} N_{i}$ - "the average growth rate of staff", T Тр $\widehat{N}_{i}$ - "the average growth rate of the number of accepted employees", Т Тр $\breve{N}_{i}$ - "the average growth rate of the number of dismissed workers", $\bar{Y}_{n}$ - "the average level of the interval series of staff, $\bar{Y}_{\hat{n}}$ - "the average level of the interval series of the number of accepted employees", $\bar{Y}_{\breve{n}}$ - "the average level of the interval series of the number of dismissed workers".

The thirteenth procedure is a characteristic of the overall dynamics of the number of staff of the structural unit. The total number of staff of the unit is determined by the formula: $N_{i}=$ $\sum_{j=4.1}^{4.9} n_{i}^{j}$, total number of accepted employees $\widehat{N}_{i}=\sum_{j=4.1}^{4.9} \hat{n}_{i}^{j}$ total number of dismissed workers $\breve{N}_{i}=\sum_{j=4.1}^{4.9} \breve{n}_{i}^{j}$. Consequently, the total number is calculated according to each post in terms of categories. 
The fourteenth procedure determines the identification of trends in the movement of personnel of a structural unit in the context of positions in accordance with the categories of professions the Ukrainian Classifier of professions. For example, the number of posts in category 4.7 - "Electro-gas welder at the automobile and semi-automobile" at the end of the year 151 persons, while during the year 108 people were released, and 50 people were taken.

The fifteenth procedure is typing the positions of the unit in accordance with the signs of the movement of personnel: the vector and intensity. For the analysis of the personnel in the context of posts, an indicator is chosen - the movement of personnel, which involves two signs of vector and intensity. The vector is defined by the "change in the ratio of occupied and dismissed workers", the intensity - the rate of change in the number of adopted and dismissed personnel. The sixteenth procedure involves the allocation of four types of posts. It is synthesized four types of positions according to the indexes of the staff turnover (vector, intensity). The first type means no dynamics; the second $-\hat{n}$ (number of employed workers) $=\check{n}$ (number of dismissed workers), the third $-\widehat{n}<\check{n}$, the fourth $-\hat{n}>\check{n}$.

Consequently, the seventeenth, the last procedure of the second stage of the diagnosis is a synthesis of trends in the dynamics of staffing of the unit. This procedure involves determining the dynamics of the state by category in accordance with each post and the vector and the intensity of movement of staff in accordance with the type.

The third stage of the diagnostic is an assessment of the professional and qualification correspondence of the employee qualities to the employer requirements that consists of seven procedures. The need for an employer in the staff has two basic characteristics: "profession" and "qualification".

Eighteenth procedure - to determine the level of the professional and qualification correspondence of the employee professional qualities $\left(\beta_{x}\right)$ to the needs of the employer $\left(\alpha_{x}\right)$, and the qualifications of the employee $\left(\beta_{y}\right)$ to the needs of the employer $\left(\alpha_{y}\right)$. Symbol $\alpha$ means the position occupied by the worker, $\alpha_{x}$ - requirements of the employer on the qualifications of the employee in relation to the profession in accordance with the position occupied, $\alpha_{y}$ - requirements of the employer on the qualifications of the employee in terms of qualifications in accordance with the position occupied, $\beta_{x}$ - professional qualities of an employee according to educational documents, $\beta_{y}$ - qualification of an employee according to the educational documents, $x$ - professional characteristics, and $y$ - qualification characteristic. There are three variants of the ratio $\alpha_{x}$ and $\beta_{x}:\langle=\rangle-$ full compliance; $\langle\approx\rangle-$ partial compliance; $\langle\neq »\rangle$ - discrepancy. In the case of a qualification, then there are such correlation variants $\alpha_{y}$ and $\beta_{y}:\langle>»-$ excess qualification; $«<»-$ insufficient qualification; $«=»-$ full compliance with qualifications [3].

To determine qualification characteristics, it is necessary to monitor the relationship between educational and educational qualifications levels and degrees of education, which are defined by normative documents, since the personnel who work at the enterprise received education at different times. For the first time, the educational and educational qualification levels are mentioned in the Law of Ukraine «About education» of 23.05.1991 \# 1060-XII: educational levels - primary general education; basic general secondary education; complete secondary education; vocational and technical education; basic higher education; Higher Education. Educational and qualification levels: skilled worker; Junior Specialist; bachelor; specialist, master's degree [4]. This law has expired.

Resolution of the Cabinet of Ministers of Ukraine "On Approval of the Regulations on Educational Qualification Levels (Graduate Education)" of 20.01.1998 p. \# 65 provides the following educational qualification levels (graduate education): skilled worker, junior specialist, bachelor, specialist and master [5]. It should be noted that the Regulation is in force, and the last changes were introduced in 2013. The letter of the Ministry of Education and Science of Ukraine of 25.04.2001 № 1 / 9-168 determined that the structure of higher education in Ukraine included the following educational qualification levels: junior 
specialist; bachelor; specialist; master [6]. Compared to previous documents there is no level - a skilled worker, there are also no mention of educational levels. The letter of the Ministry of Education and Science is also determined as not having expired.

The Law of Ukraine "On Higher Education" of 17.01.2002 \# 2984 stipulated that the structure of higher education includes educational and educational-qualification levels. Educational levels: incomplete higher education; basic higher education; full higher education; educational qualification levels: junior specialist; bachelor; specialist, master's degree [7]. It should be noted that between the above normative documents is followed by partial continuity. Law of Ukraine "On Higher Education" of 01.07.2014 \# 1556-VII It is radically different from previous documents, because it is oriented towards European standards and determines the level of higher education: the initial (short cycle), the first (bachelor), the second (master's), the third (educational-scientific), the scientific level. Higher education at each level of higher education involves the award of a corresponding degree of higher education: junior bachelor, bachelor, master, doctor of philosophy, doctor of sciences [8]. It should be noted that modern machine building requires the expansion of the spectrum of functions of junior specialists, which determines their significance in the staffing structure.

Consequently, on the basis of the analysis of normative documents, a combined system of characterization was proposed " $y$ ", which also uses educational levels and educational qualification levels (table 1).

Table 1. Combined system of characterization " $y$ "

\begin{tabular}{|l|l|}
\hline \multicolumn{1}{|c|}{ Qualification } & \multicolumn{1}{c|}{ Definition } \\
\hline $\begin{array}{l}\text { 1. Complete secondary } \\
\text { education }\end{array}$ & $\begin{array}{l}\text { A person who does not have an educational qualification level has } \\
\text { completed a secondary school of three levels, that is, an unskilled } \\
\text { worker. }\end{array}$ \\
\hline $\begin{array}{l}\text { 2. Vocational and } \\
\text { technical education }\end{array}$ & $\begin{array}{l}\text { A person who has an educational qualification level - a skilled worker, } \\
\text { according to the Law "On Education" dated May 23, 1991, No. 1060- } \\
\text { XII, graduated from a vocational and technical institution (college). }\end{array}$ \\
\hline $\begin{array}{l}\text { 3. Incomplete higher } \\
\text { education }\end{array}$ & $\begin{array}{l}\text { A person with an educational qualification level of a junior specialist } \\
\text { is currently a junior bachelor in the Law on Higher Education and an } \\
\text { initial level (in the Law "On Education" junior specialist and junior } \\
\text { bachelor "). Training is provided by: technical colleges and colleges. }\end{array}$ \\
\hline $\begin{array}{l}\text { 4. Basic higher } \\
\text { education }\end{array}$ & $\begin{array}{l}\text { A person who has an educational qualification bachelor's degree. } \\
\text { Provide colleges, other higher education institutions of the second- } \\
\text { fourth accreditation level. In the current Law "On Higher Education", } \\
\text { an educational degree obtained at the first level of higher education } \\
\text { and awarded by a higher education institution. }\end{array}$ \\
\hline 5. Higher Education & $\begin{array}{l}\text { A person who has an educational or qualification level of a specialist } \\
\text { or a masters degree. Preparations are provided by higher education } \\
\text { institutions. }\end{array}$ \\
\hline
\end{tabular}

Source: Authors.

Thus, according to Table. 1, five qualification characteristics are defined.

The profession is defined according to the Ukrainian Classifier of professions as the ability to perform such work, which requires a person of a certain qualification. In turn, the specialty is a complex of skills, skills and knowledge acquired during the learning process. So, for the title of the position the occupations used are given in the Classifier. At the same time, in the job description according to each post should indicate the specialty that the employee must possess. Therefore, to determine the characteristics " $x$ " you need to use: CMU Resolution \# 1117 of 1110.2007 "On Approval of the State List of Professions for the Training of Qualified Workers in Vocational Education Institutions" [9]; CMU Resolution \# 839 of 20.072007 "On Approval of the List of Specialties on which the Training of 
Specialists in Higher Educational Institutions under the Educational-Qualification Level of a Junior Specialist is carried out" [10]; CMU Resolution \# 1719 of 13.12. 2006 "On the List of Directions for the Training of Specialists in Higher Educational Institutions for the Baccalaureate Degree" [11] and the CMU Resolution \# 787 of 27.08.2010 "On Approval of the List of Specialties, according to which the training of specialists in higher educational establishments is carried out according to the educational and qualification levels of a specialist and a master's degree ", which have now become null and void [11].

The modern training of applicants is in accordance with the resolution of the Cabinet of Ministers of Ukraine of 29.04.2015, \# 266 "On Approval of the List of Fields of Knowledge and Specialties for which Higher Education Institutions are Prepared" and which should be used from 2019 [12].

Consequently, professional characteristics are set according to the specialty (direction of training) specified in the education document. However, the demand for professionals is determined not by the level of training, but by how well they are prepared in the light of the requirements of employers.

The nineteenth procedure involves the allocation of 9 conformity classes: A, B, C, D, E, $\mathrm{F}, \mathrm{G}, \mathrm{H}, \mathrm{L}$, which can be divided into three groups. The first group of classes A, B, C is characterized by the fact that $\alpha_{x}=\beta_{x}$. Class A corresponds to the full compliance of the employer's professional qualification requirements with regard to the qualities of the worker $\alpha_{x}=\beta_{x}$ and $\alpha_{y}=\beta_{y}$. Class B is characterized $\alpha_{x}=\beta_{x}$ and $\alpha_{y}<\beta_{y}$, that is, the profession has full compliance, and the qualification of the employee exceeds the employer's requirements for the position occupied. Class $\mathrm{C}$ is characterized $\alpha_{x}=\beta_{x}$ and $\alpha_{y}>\beta_{y}$, means compliance with the professional requirements of the employer, but the employee has a lower qualification.

The second group of classes $\mathrm{D}, \mathrm{E}, \mathrm{F}$ is characterized by the fact that $\alpha_{x} \approx \beta_{x}$. Class D is characterized $\alpha_{x} \approx \beta_{x}$ and $\alpha_{y}=\beta_{y}$. Class $\mathrm{E}$ is characterized $\alpha_{x} \approx \beta_{x}$ and $\alpha_{y}<\beta_{y}$, the profession partially meets the requirements of the position, and the qualification of the employee is greater than necessary. Class $\mathrm{F}$ is characterized $\alpha_{x} \approx \beta_{x}$ and $\alpha_{y}>\beta_{y}$, the profession partially meets the requirements of the position, and the qualification of the employee is less than necessary.

Third group of classes G, H, L is characterized $\alpha_{x} \neq \beta_{x}$. Class G is characterized $\alpha_{x} \neq$ $\beta_{x}$ and $\alpha_{y}=\beta_{y}$, which implies compliance with the requirements of the employer to the qualities of the work regarding qualifications and professional misconduct. Class $\mathrm{H}$ is characterized $\alpha_{x} \neq \beta_{x}$ and $\alpha_{y}<\beta_{y}$, provides for the lack of correspondence between the professional requirements of the employer and the qualities of the employee, and the qualifications of the employee more than required occupation. Class L is characterized $\alpha_{x} \neq$ $\beta_{x}$ and $\alpha_{y}>\beta_{y}$, the lack of correspondence between the professional requirements of the employer and the qualities of the employee, and the qualification of the employee is less than the occupied position

The twentieth procedure - the definition of indicators to determine the level of professional qualifications compliance or inconsistency. These are indicators that are marked with symbols: $n_{i}^{\kappa / j}-$ number of staff to the end period $i, k$ - conformity class $\{\mathrm{A}, \mathrm{B}, \mathrm{C}, \mathrm{D}, \mathrm{E}, \mathrm{F}, \mathrm{G}, \mathrm{H}, \mathrm{L}\}$ and $j=\{4.1,4.2,4.3,4.4,4.7,4.8,4.9\}, n_{\mathrm{i}}^{k}-$ the number of staff of the conformity class at the end period $i, d_{n_{i}^{k}}$ - staff share of the relevant class in the total number of employees of unit, $d n_{k}^{j}$ - staff share $j$ - category in conformity class $k$. The total number of the unit staff according to the class is indicated: $\sum n_{i}^{k}$, and the total number of the staff according to the category $-\sum n_{i}^{j}$.

The twenty first procedure - the use of absolute indicators made it possible to form synthetic indicators for analysis: $T_{n p}^{\Omega} .\left(n_{i}^{k}\right)$, - "chain rate of increase the number of personnel 
of conformity class", $\bar{T}_{\text {пр. }}^{\text {л }} k$ - "the average growth rate of the number of personnel of conformity class", $\bar{Y}_{k}$ - "the average level of the interval series of staff of the classes", and $k=\{\mathrm{A}, \mathrm{B}, \mathrm{C}, \mathrm{D}, \mathrm{E}, \mathrm{F}, \mathrm{G}, \mathrm{H}, \mathrm{L}\}$.

The twenty-second procedure is the implementation of the characteristics of the professional qualification of the staff of the structure unit in accordance with the classes in terms of the categories of Ukrainian Classifier of professions.

The twenty-third procedure is to find out the value of the coefficient of professional and qualification correspondence $\left(K_{i}^{p q c}\right)$. Since staffing means one hundred percent correspondence of the interests of the employee and employer, the value $K_{i}^{p q c}=1$. But the current state of staffing of Ukrainian machine-building enterprises is indicative of an imperfect HR policy. Therefore, it is proposed to introduce a scale of coefficients $\left(\mathrm{m}^{k}\right)$ for each conformity class (table. 2) [3].

Table 2. Coefficients according to the conformity class

\begin{tabular}{|c|c|c|c|c|c|c|c|c|c|c|}
\hline $\mathbf{k}$ & $\mathbf{A}$ & $\mathbf{B}$ & $\mathbf{C}$ & & $\mathbf{D}$ & $\mathbf{E}$ & $\mathbf{F}$ & $\mathbf{G}$ & $\mathbf{H}$ & $\mathbf{L}$ \\
\hline$m^{k}$ & 1 & 0.7 & 0.6 & & 0.8 & 0.5 & 0.4 & 0.3 & 0.2 & 0.1 \\
\hline
\end{tabular}

Source: Authors.

According to Table 2 indicator value $m^{A}=1$, since this class characterizes the full compliance of the qualities of the employee with the requirements of the employer. Class D has a value of 0.8 , because it describes the states in which the employee does not fully realize his skills and abilities. Class $\mathrm{B}$ has been assigned 0.7 because the class extends the professional qualities of the employee. Class $C$ is characterized by $m^{C}=0,6$, this class is typical for those employees who have experience in the company in accordance with the received profession, which compensates for the lack of qualifications. Class $\mathrm{E}$ has a coefficient of 0.5 , is disadvantageous to both parties. A similar to the previous one - class $\mathrm{F}$ - has $m^{F}=0,4$.

The most risky classes are unprofitable for the enterprise are G, H, L. Class G has a value of 0,3 , because the knowledge and skills of the employee absolutely do not meet the requirements of the position, although the qualification is characterized as $\alpha_{y}=\beta_{y}$. Class $\mathrm{H}$ has $m^{H}=0,2$. Class I has value of the coefficient 0,1 . In general, the presence of employees of this class indicates problems in the staffing of the enterprise, because an employee can not perform work in accordance with his position.

Consequently, in accordance with the given coefficients, the calculation of the integral index of professional qualification correspondence in terms of expression:

$$
K_{i}^{p q c}=\frac{\sum_{k}^{9} m^{k} \cdot n_{i}^{k}}{N_{i}}
$$

The twenty-fourth procedure, the last procedure of the third stage of diagnosis, is the generalization of revealing the insufficient level of professional and qualification correspondence of the personnel by distributing the staff to the conformity class. Clarification of the value of the coefficient of professional and qualification correspondence will determine the degree of compliance of the qualities of personnel to the tasks of the enterprise.

\section{Discussion and Conclusion}

The choice of diagnostics as a tool for scientific knowledge is substantiated by the ability to identify problems, their causes and formulate recommendations for their elimination. The first stage of the diagnostic assessment involves an analysis of the staff compliance with the 
production and economic activities of the enterprise and consists of nine procedures. The second stage of the diagnostic assessment is the synthesis of types of positions on the basis of the movement of the personnel at the enterprise, which consists of eight procedures. The third stage of the diagnostic is an assessment of the professional and qualification correspondence of the employee qualities to the employer requirements that consists of eight procedures. The diagnostic process consists of three stages and includes 24 procedures, which are complementary and interferential.

Using deductive method and analogy has allowed to choose as the research plane the leading link in the technological process of the enterprise of the machine-building complex.

Instrumentarium of the diagnosis involves the use of a system of indicators that characterize financial and economic activity of the enterprise and personnel policy; the staff movement and the level of professional and qualification correspondence. According to the selected indicators, the synthetic ones are defined: the average level of the interval series of dynamics with equal intervals, the chain and average growth rate. Thus, the selected indicators will allow to carry out diagnostics of staffing of the domestic machine-building enterprises, to identify the problems and causes of their occurrence, which will form a way for further modernization of staffing.

\section{References}

1. O. Zakharova, Features of estimation of movement of personnel of the enterprise. Formation of a market economy: a collection of scientific works Special Issue in the 21st Century: Recent Trends, Social Dimension, Innovative Development, pp. 439-452 (2012)

2. Classifier of professions DK 003: 2010, 746 (2010)

3. K. Pryakhina, Personnel: assessment of professional qualification correspondence. Economic Sciences, 2(25), 10-14 (2017)

4. “On Education": Law of Ukraine dated May 23, 1991 No. 1060-XII (1991)

5. "On Approval of the Regulation on Educational-Qualification Levels (Graduate Education)": Resolution of the Cabinet of Ministers of Ukraine dated January 20, 1998 No. 65. Official Bulletin of Ukraine. 1998. No. 3. Art. 108 (1998)

6. "About educational qualification levels (degree education)": Letter of the Ministry of Education and Science of Ukraine of 25.04.2001 № 1/9-168. Guide. 2001. 08. № 30. (2001)

7. “On Higher Education” Law of Ukraine of January 17, 2002 No. 2984-III (2002)

8. “About higher education”: Law of Ukraine dated 01.07.2014 № 1556-VII (2014)

9. "On Approval of the State List of Professions for the Training of Qualified Workers in Vocational Education Institutions": Decree of the Cabinet of Ministers of Ukraine dated September 11, 2007 No. 1117. Official Bulletin of Ukraine. No. 70. Art. 2656. p. 11 (2007)

10. "On approval of the list of specialties for which the training of specialists in higher educational institutions is carried out at the educational qualification level of a junior specialist": Resolution of the Cabinet of Ministers of Ukraine dated 20.06.2007 No. 839. Official Bulletin of Ukraine. No. 46. Art. 1877. p.23 (2007)

11. "On approval of the list of specialties for which the training of specialists in higher educational institutions is carried out at the educational and qualification levels of a specialist and master": Resolution of the Cabinet of Ministers of Ukraine dated August 27, 2010 No. 787. Government Courier. No. 175 (2010) 
12. "On Approval of the List of Fields of Knowledge and Specialties under which Higher Education Institutions are Prepared": Resolution of the Cabinet of Ministers of Ukraine dated April 29, 2015 No. 266. Government Courier. No. 102 (2015)

13. O. Maslak, N. Grishko, K. Vorobiova, O. Hlazunova, M. Maslak, Developing the intrafirm technology transfer system at the industrial enterprise based on matrix approach. Problems and Perspectives in Management, 15(3), 242-252 (2017) 